\title{
ENTENDEU OU QUER QUE EU DESENHE? TRANSIÇÕES FAMILIARES ATRAVÉS DA VISÃO SISTÊMICA ${ }^{\star}$
}

\author{
Igor Reszka Pinheiro $\star$ \\ Maria Aparecida Crepaldi ${ }^{\star \star \star}$ \\ Roberto Moraes Cruz ${ }^{\star \star \star}$
}

\begin{abstract}
Resumo
Este ensaio teórico tem como objetivo apresentar a teoria sistêmica como um meio de filtrar o caos em que ocorrem as transições familiares, através do recurso de imagens que sintetizam o emaranhado das suas interações. Examinou-se, para tal, os alicerces da teoria sistêmica, destrinchou-se as transformações básicas quando da interação entre células individuais e contextos coletivos e, por fim, explanou-se as transições familiares mais comuns. Entende-se que os prejuizos do possivel reducionismo acarretado pelas representações gráficas são plenamente compensados pelo ganho em clareza e objetividade que as ilustrações oferecem para cada processo, facilitando a sua compreensão, manipulação e associação.

Palavras-chave: Teoria Sistêmica; homeostase; vincularidade; transições familiares.

\section{Got IT? UNDERSTANDING FAMILY TRANSITIONS THROUGH THE SYSTEMS PERSPECTIVE}

\begin{abstract}
This theoretical essay presents the system theory as a mean to filter out the chaos in which family transitions occurs, by the use of images that summarize and disentangle its interactions. For this purpose, it was examined the foundations of systems theory, it was unraveled the basic transformations regarding individual cells and collective contexts and, finally, it was explained the most characteristics family transitions. The proposed reductionism losses are considered offset by the gains in clarity and objectivity that the illustrations provides for each process, facilitating their understanding, manipulation and association.

Keywords: Systems Theory; homeostasis; attractiveness; family transitions.

\footnotetext{
${ }^{\star} \mathrm{O}$ primeiro autor deste artigo agradece o auxílio financeiro concedido pela Capes.

$\star \star$ Possui graduação em Design pela Universidade Federal de Santa Catarina. Doutorando em Psicologia na Universidade Federal de Santa Catarina. E-mail: pinheiro_ir@yahoo.com.br

$\star \star \star$ Psicóloga. Doutora em Saúde Mental pela UNICAMP. Pós-Doutorado pela Universidade do Québec em Montreal e pela Faculdade de Medicina de Ribeirão Preto-USP. E-mail: maria.crepaldi@gmail.com

$\star \star \star \star$ Psicólogo. Doutor em Engenharia de Produção - Ergonomia pela Universidade Federal de Santa Catarina. Pósdoutoramento em Métodos e Diagnóstico na Universidade de Barcelona. E-mail: robertocruzdr@gmail.com
} 
É difícil contestar o fato de que as famílias, assim como as pessoas, nascem, crescem, se reproduzem e morrem. É possível, porém, questionar a sequência linear e aparentemente isolada desses acontecimentos, já que a estabilidade da configuração desse primeiro círculo de socialização humana demanda constantes adaptações a um meio caótico e a organização interna de indivíduos também em transformação. Tais características, mais que deporem a favor da complexidade das transições familiares, evidenciam a natureza sistêmica desses grupos, cuja compreensão progride de forma lenta e fragmentada (KREPPNER, 2000).

Oliveira e colaboradores (2008), por exemplo, ao revisarem a produção científica sobre as diferentes configurações familiares nos últimos cinquenta anos, apesar de sugerirem uma intrincada disposição de inter-relacionamentos, pouco, ou nada, estruturam os diferentes tópicos levantados em artigos nacionais e internacionais, transparecendo mais uma variada gama de alternativas metodológicas que conteúdos de caráter complementar. Dentre a miríade de amostras (crianças, idosos, díades etc.), situações específicas (monoparentalidade, divórcio, recasamento etc.) e conteúdos temáticos (consequências positivas, negativas, neutras etc.) dos materiais levantados pelos autores citados, não se sabe até que ponto há dependência, influência, sequência ou causalidade.

Em um estudo já clássico, porém, Bronfenbrenner (1977) adverte que o verdadeiro entendimento do contexto ecológico humano requer a superação do modelo de pesquisa tradicional que se limita a acessar somente o efeito direto da interação entre dois elementos da família de cada vez (relação mãe-filho, criança-geografia, pai-trabalho, escola-vulnerabilidade etc.). Para esse mesmo autor, o minimalismo experimental justificado no rigor científico serve, tão somente, como uma fonte de dados para a compreensão dos arranjos estruturais que acomodam, progressivamente, o organismo humano ao longo de sua vida. Em outras palavras, acredita-se que, no momento, é mais relevante saber como se encaixam as informações já obtidas que angariar qualquer nova evidência isolada.

Seria possível, então, criar um cenário que abrangesse as personagens mais presentes e significativas desses estudos? Seria possível descrever a complexidade da rede familiar se desenvolvendo ao longo do tempo e envolvendo toda a constelação de relacionamentos existentes nos primeiros círculos sociais? Seria possível fundamentar a interpretação das transições familiares através de um conjunto único de modelos? Acredita-se que sim e, ainda, que tal panorama já exista: a própria teoria sistêmica (VON BERTALANFFY, 1950b; COX; PALEY, 1997). A dúvida, neste caso, passa a ser de que forma operacionalizar o entendimento comum dessa perspectiva e, em tempo, traduzir as dinâmicas lineares já estudadas em padrões de uma mesma rede multidirecional (JOHNSON, 2008).

Destarte, este artigo tem como objetivo, por meio da utilização de imagens que sintetizam o emaranhado de interações previstas pela perspectiva sistêmica, filtrar "o caos" em que ocorrem as transições familiares. Espera-se que as ilustrações, sendo suportes do eidetismo visual, sejam capazes de sintetizar a complexidade sem incorrer em grandes reducionismos ou mecanicismos (MASSIRONI, 1982), facilitando a compreensão, a manipulação e a associação das partes que compõem 
o corpus de conhecimento dos diferentes níveis de configurações sociais. Os benefícios dessa proposta, além de atingirem os estudantes interessados em iniciar-se na visão sistêmica, voltam-se para todos aqueles ocupados no trato da família, bem como em associar e confrontar gradualmente o conhecimento das relações humanas, mesmo que este esteja disponível em diferentes contextos verbais.

Na primeira seção, a seguir, examinar-se-á o recorte teórico adotado no texto, ou seja, os alicerces da teoria sistêmica, suas forças constituintes e o arranjo fractal dos subsistemas. Depois, passar-se-á para o estudo das transformações básicas quando da interação entre células individuais e contextos coletivos, dentre as quais se arrolam a sorte, a resiliência, a inteligência e a criatividade. Por fim, explanar-se-ão as mais características transições familiares, movimentos que dizem respeito ao nascimento, ao crescimento, à reprodução e à morte dessas redes sociais. Este ensaio teórico se conclui com uma proposta de arranjo harmônico e com direcionamentos para novas pesquisas.

\section{Os SISTEMAS}

A teoria sistêmica, antes de mais nada, consiste da generalização do modelo organicista (COX; PALEY, 1997; VON BERTALANFFY, 1977), segundo o qual o universo ou a natureza podem ser interpretados como um gigantesco organismo vivo. Esta metáfora, ao extrapolar o domínio da embriologia, no qual o processo de diferenciação celular é submetido a controles externos, atinge o campo da psicologia, sugerindo uma concepção de desenvolvimento biopsicossocial análoga, em que o organismo humano se submete à regulação transitória do meio. Nessa concepção, portanto, é impensável a absoluta autonomia ou a completa liberdade individual, já que, sendo os seres humanos sistemas abertos conforme argumenta Von Bertalanffy (1950a, 1950b e 1977), no mínino, o todo sempre influenciará cada unidade.

Diferentemente da crença comum, porém, ao mesmo tempo em que o meio exerce influência sobre as suas partes constituintes, cada elemento autônomo também influencia o seu contexto (BRONFENBRENNER; CECI, 1994), com a mesma intensidade e direção, mas no sentido oposto. Dá-se o nome de "socialização" à prevalência da estabilidade contextual, que conforma, à sua face, cada partícula pessoal, e de "inovação" à reação vitoriosa individual. Tais transformações, todavia, só ocorrem quando não há equilíbrio entre a parte e o todo, pois, assim como em qualquer organismo vivo, a diretriz magna dos sistemas é a homeostase, característica que busca o ajuste de pessoas a meios tanto positivos quanto negativos (BATESON, 1979). Na Figura 01, por exemplo, essa peculiaridade pode ser vista como o distanciamento entre a célula individual e o epicentro do seu ambiente, zona de maior retorno ou lucro para ela. 


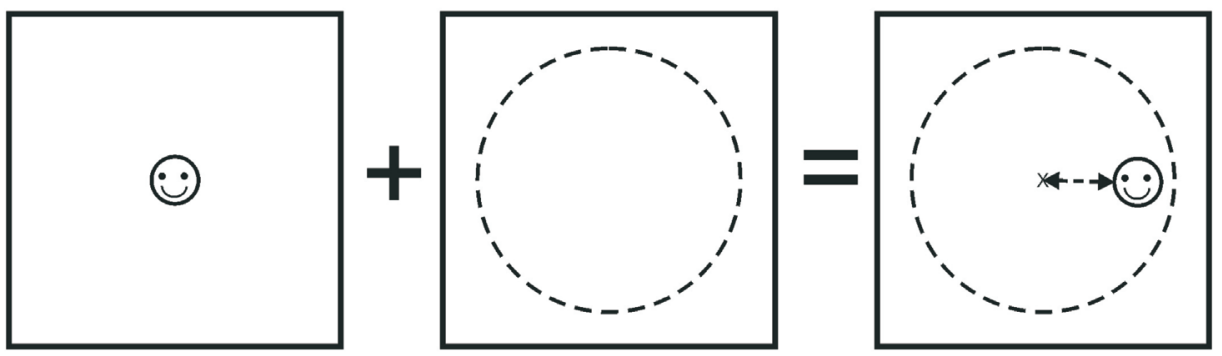

Figura 01: Pessoa + Meio $=$ Homeostase [Fonte: Autor $]$

Com exceção dos arranjos experimentais, é bastante improvável, contudo, que um sistema qualquer seja composto por apenas uma unidade. $\mathrm{Na}$ presença de duas ou mais partículas, nesse caso, distingue-se a força da vincularidade (Fig. 02), segunda pressão atuante em qualquer coletividade. Ramires (2004, p. 187) aponta para o fato de que, em se tratando de pessoas, esses vínculos "são elos de ligação, de natureza emocional, interpessoais ou intrapessoais, permanentemente presentes e interativos; são imanentes e ao mesmo tempo potencialmente transformáveis; comportam-se como uma estrutura e são polissêmicos, assumindo vários significados".

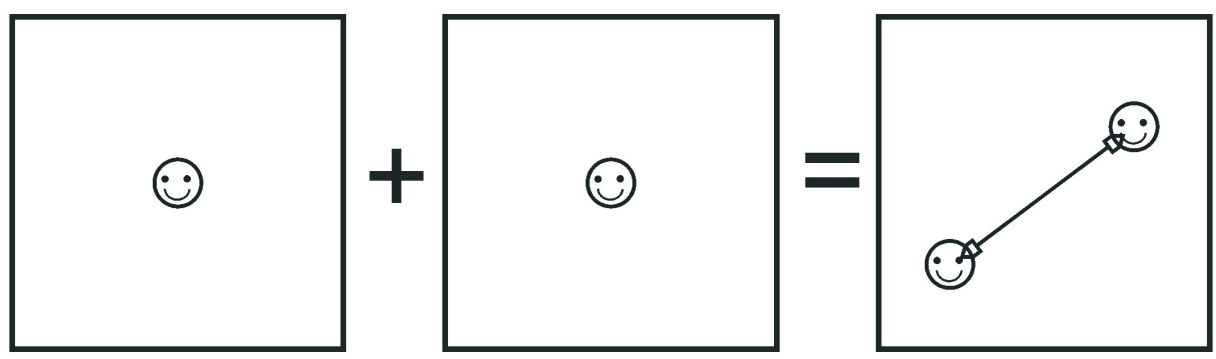

Figura 02: Pessoa + Pessoa $=$ Vincularidade $[$ Fonte: Autor $]$

É pertinente ressaltar, então, que a homeostase e a vincularidade são conceitos intercambiáveis, logo intrinsecamente inseparáveis, se considerados diferentes níveis sistêmicos adjacentes. A homeostase psicológica de um sistemapessoa em uma família, por exemplo, é igual à gestalt da sua vincularidade para com as demais pessoas no sistema-família. Assim, por mais que a homeostase de um sistema implique obrigatoriamente no rearranjo de suas partes, é metodologicamente interessante diferenciá-la como a influência recursiva entre o todo e a sua unidade básica (BATESON, 1972; CERVENEY, 2004), uma vez que, do contrário, os diferentes pontos de vista pessoais tornam impossível gerenciar a intersubjetividade descrita por Vasconcellos (2002).

Nisso, mesmo sem o acréscimo de nenhum outro agente, somente da combinação de pessoas, contexto e ambas as forças de interação, emerge o típico cenário de complexidade tão característico dos sistemas nas suas mais diversas configurações (Fig. 03). Ressalta-se, no entanto, que há distinção entre a definição coloquial atribuída à complexidade, a qual sugere confusão, aleato- 
riedade e desordem, e o conceito científico desse termo, que passa a ser entendido como um nível específico de organização tangente ao caos (JOHNSON, 2008). Sistemas complexos, por natureza, encontram-se sempre no limiar entre os pontos de estase e entropia, e estão constantemente se desenvolvendo ao redor desse estado crítico (BATESON, 1979).

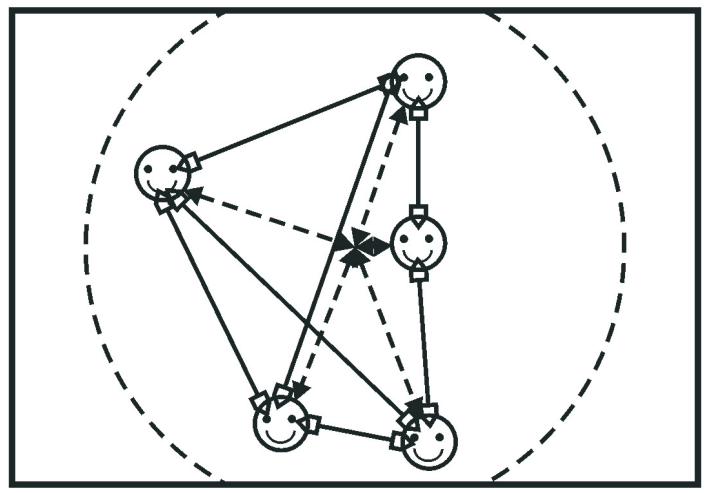

Figura 03: Sistema Complexo [Fonte: Autor]

Existem quatro princípios gerais da teoria sistêmica, porém, cujas propriedades favorecem a compreensão e a organização dos conjuntos complexos (COX; PALEY, 1997). O Holismo (1), primeiramente, enuncia que o todo de um sistema é sempre maior que a soma das suas partes, bem como possui propriedades que não podem ser determinadas pela combinação de cada parcela. A Auto-estabilidade Adaptativa (2), em seguida, consiste da busca por equilíbrio homeostático, o qual compensa as mudanças ambientes através da re-organização coordenada das forças internas do sistema. Depois, a Auto-organização Adaptativa (3), complementar à característica anterior, se refere à busca por equilíbrio gravitacional, ou à habilidade dos elementos singulares encontrarem a harmonia dos seus próprios vínculos. Já a Estruturação Hierárquica (4), por fim, diz respeito ao fato de que todo sistema é composto por subsistemas que, por sua vez, são sistemas de subsistemas menores ainda.

Esse último princípio, mais que se referir às relações diádicas, triádicas ou n-ádicas, advindas da análise combinatória dos elementos de um conjunto qualquer, alude à característica fractal inerente aos sistemas, a qual dita que cada unidade também é o todo de uma dimensão inferior, ou, simetricamente, que a totalidade é só uma célula de uma dimensão superior. Visualiza-se essa particularidade na Figura 04 que, por exemplo, exibe duas dimensões fractais adjacentes: um sistema social cuja unidade é a pessoa e; um sistema individual cuja unidade é o cluster de pensamento. Quanto melhor for a sobreposição ou o encaixe, nesse caso, entre o sistema individual e o sistema social, menor será o estresse provocado pela constante busca de equilíbrio (BRONFENBRENNER, 1969). 


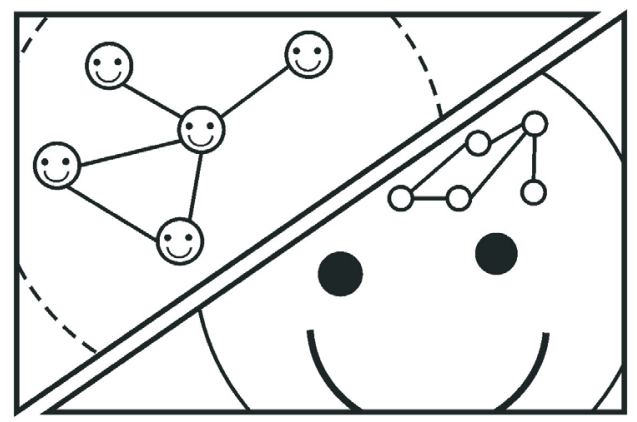

Figura 04: Duas Dimensões de um Sistema Fractal [Fonte: Autor]

É válido lembrar, entretanto, que a harmonia sistêmica dispensa uma composição plenamente homogênea de unidades, já que a representação que esses elementos fazem da dimensão superior é sempre mais acanhada e menos intrincada que o ambiente em si (princípio do holismo). Assim, em se tratando de pessoas, pode-se dizer que indivíduos com diferentes formas de pensar são sim capazes de se adaptar a um mesmo contexto maior, mesmo que com desiguais probabilidades de sucesso, desde que haja espaço e oportunidade para cada um deles. A Figura 05 ilustra esse fato ao exibir os diferentes locais que os indivíduos A, B, C e D poderiam ocupar otimamente no seu sistema coletivo, dadas as suas características pessoais. Ao mesmo tempo em que somente as diferenças garantem a coexistência sistêmica, somente as semelhanças (posição B/D na Fig. 05) possibilitam a cooperação ou a competição, atitudes que irão variar dependendo da abundância ou da escassez dos recursos disponíveis para os sujeitos envolvidos nessa relação.

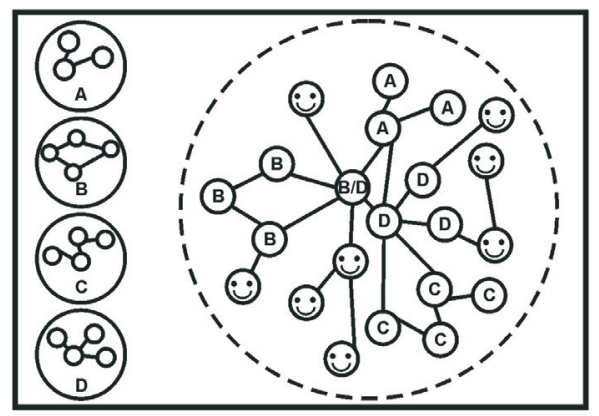

Figura 05: Sistema Holístico [Fonte: Autor]

Finalmente, antes de se iniciar o relato das transformações dos conjuntos complexos, ainda resta mencionar que existem outras perspectivas sistêmicas que vão além da proposta deste artigo, mas, que são bastante utilizadas no estudo das transições familiares, como a cibernética (BATESON, 1972; WATZLAWICK; WEAKLAND; FISCH, 1977) e o modelo bioecológico do desenvolvimento humano (BRONFENBRENNER, 1979, 1986). No modelo bioecológico de Bronfenbrenner (1986), a guisa de exemplo, além das relações de cooperação e competição entre indivíduos de um mesmo nível sistêmico, pode-se discriminar um conjunto de interconexões que se estendem por cinco dimensões distintas, os micro, os meso, os 
exo, os macro e os cronossistemas. Independentemente da taxonomia empregada, porém, acredita-se que o mínimo múltiplo comum entre os ambientes caóticos seja as forças de estabilidade e de mudança, as quais, sempre que em desequilíbrio, impelem invariavelmente os indivíduos ou o meio a uma nova configuração.

\section{AS TRANSFORMAÇÕES BÁSICAS}

Dentre as infinitas configurações que duas dimensões adjacentes de um sistema podem apresentar, existem basicamente dois estados a serem discernidos: a sua consonância e; a sua disparidade. Quando um indivíduo reflete exatamente a sua coletividade, diz-se que ambos estão em consonância, harmonia ou, mesmo, equilíbrio (Fig. 06). Dá-se o nome de "sorte" a tal configuração uma vez que o acaso se apresenta como um dos principais elementos geradores desse estado. Hayes (1989), todavia, distingue quatro diferentes níveis de envolvimento com a sorte, mesmo que de origem não-intencional: 1) pura sorte; 2) sorte por persistência (mais tentativas aumentam a possibilidade estatística de algo acontecer ao acaso); 3) sorte por preparo (ter o conhecimento certo na hora certa) e; 4) sorte por dotação (dispor de uma qualidade em particular indispensável ao contexto). Em qualquer um desses casos, a parte que se encontra em equilíbrio com o todo não está propensa a mudanças, já que o ambiente prontamente lhe oferece um retorno ótimo.

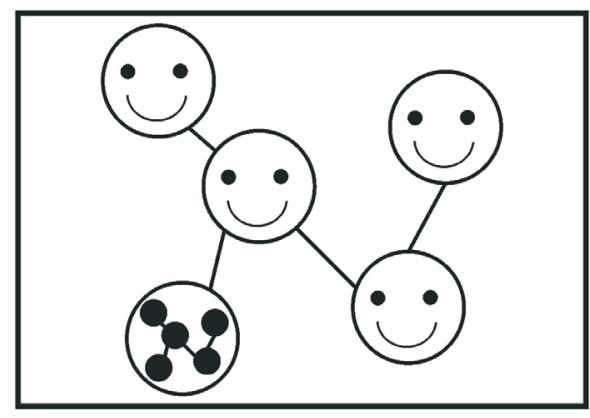

Figura 06: Sorte [Fonte: Autor]

Por outro lado, quando a organização interna de um indivíduo é diferente da forma com que seus pares se relacionam, há o referido estresse ou tensão que, ao manter-se por muito tempo, acarreta na exaustão física (CALAIS et al., 2007) e no adoecimento mental (CRUZ, 2005). Antes que isso ocorra, contudo, o mecanismo de homeostase age no sentido de equilibrar essa disparidade, fazendo com que a pessoa atue de diferentes formas na sociedade.

A adaptação ao meio ocorre através da resiliência, da inteligência e/ou da criatividade, conceitos frequentemente intercambiáveis quando simplifica-se as suas definições e ignora-se os seus papeis sistêmicos. A diferenciação existe e, aliás, é fundamental para a pesquisa e a intervenção, já que cada uma dessas alternativas necessita de qualidades específicas, as quais podem ser medidas e aprendidas ao longo da vida. 
A flexibilidade, por exemplo, talvez seja a competência mais relevante à resiliência, uma vez que esse fenômeno consiste do ajuste do indivíduo em relação à sua rede (Fig. 07). A habilidade humana de crescer e prosperar, independentemente dos riscos ou das adversidades, está alicerçada na capacidade de adequação aos momentos de crise (BRENDTRO; LONGHURST, 2005). A primeira forma de superação da diferença individual é, portanto, enquadrar-se ao meio, não apenas copiando o que já se faz, mas desenvolvendo o padrão psicológico e emocional mais adequado à necessidade que se apresenta. Os resilientes, logo, tendem a superar as expectativas de seus pares, já que atingem níveis ótimos de desempenho, o que pode ser mensurado através da sua velocidade de acomodação.
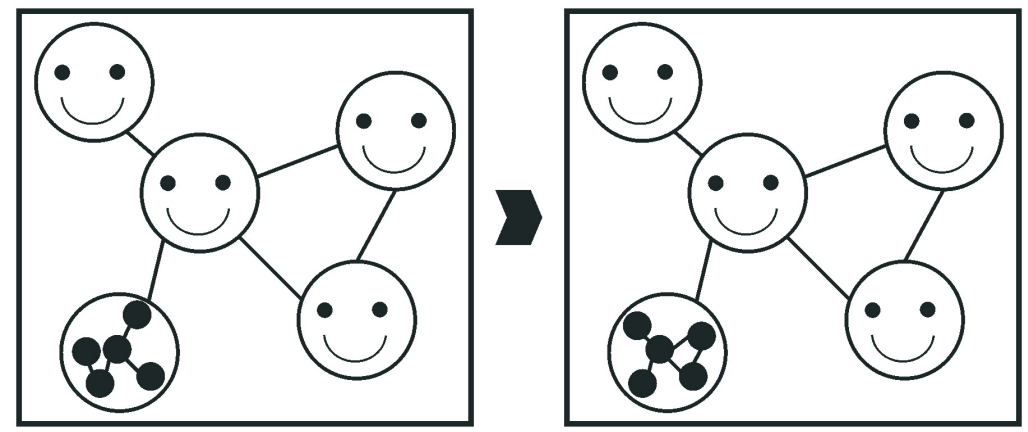

Figura 07: Resiliência [Fonte: Autor]

O segundo caso de transformação sistêmica não requer a mesma flexibilidade, visto que a pessoa não terá de mudar o seu padrão mental, mas sim encontrar o local onde as suas exatas características maximizam os seus proventos (Fig. 08). A inteligência, por conseguinte, apresenta-se como uma alternativa à resiliência ao questionar, não as configurações, mas as posições na macro-rede, encontrando brechas para a aproximação do local de maior centralidade. Essa definição de inteligência se aproxima do que Kuncel, Hezlett e Ones (2004) chamam de "conhecimento prático e declarativo", consistindo do engajamento em uma tarefa cuja sabedoria a respeito dos fatos, das regras, dos princípios e dos procedimentos que compõem os prerrequisitos de sua execução bem sucedida, indica retorno máximo. É muito mais inteligente uma pessoa magra e ágil, por exemplo, buscar tarefas que exijam velocidade, que se esforçar continuamente para executar um trabalho que dependa de grande força muscular. O seu desenvolvimento e mensuração, por conseguinte, está diretamente vinculado ao ato da tomada de decisão, o qual equaciona o tamanho de uma possível recompensa e o tempo necessário no trajeto pra obtê-la (BOGACZ, 2006). 

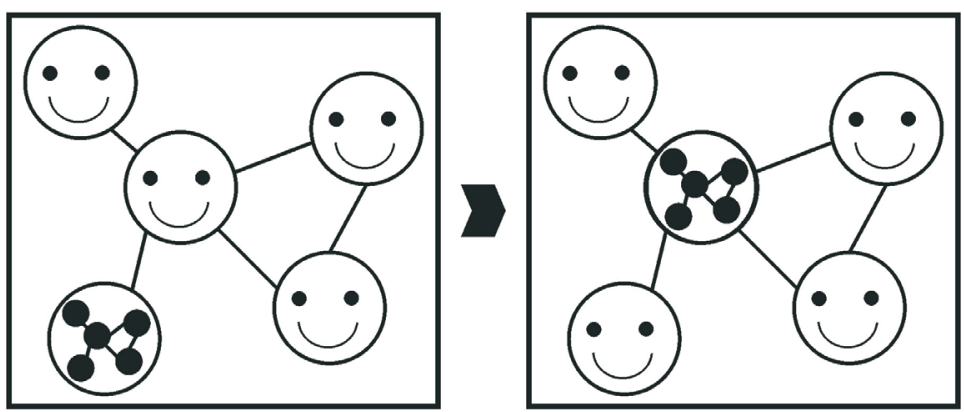

Figura 08: Inteligência [Fonte: Autor]

Por fim, existe uma última alternativa quando não se deseja ou não se consegue adaptar-se ao lugar ou mudar-se de lugar: mudar o lugar! A criatividade é o mecanismo psicossocial de homeostase baseado na transformação do contexto, tendo como foco o indivíduo, em geral utilizada quando é necessário quebrar a inércia do sistema (Fig. 09). Sternberg (1999) descreve sete formas com que a criatividade, dessa forma, pode alterar o seu ambiente: replicação; redefinição; incremento; incremento progressivo; redirecionamento; reconstrução e; reinicialização. Cada qual em particular, mais que propor uma nova configuração ao coletivo, guia a construção de um modelo conjunto, improvável de se atingir espontaneamente. Se todas as pesquisas em física apontam para o Big Bang como teoria de criação do universo, o estudioso que engajar sua comunidade em uma ideia alternativa não será inteligente nem resiliente, será, logo, criativo.
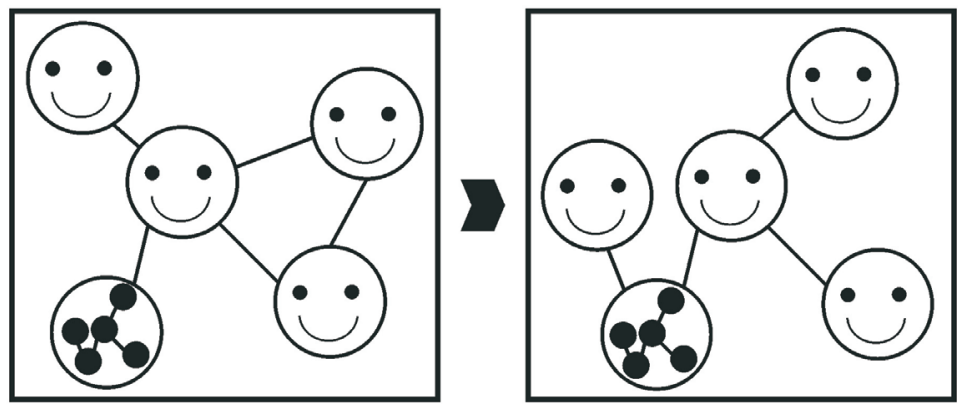

Figura 09: Criatividade [Fonte: Autor]

Visualiza-se a atuação múltipla de uma mesma célula individual através da resiliência e da inteligência, bem como por meio da inteligência e da criatividade, mas jamais a coexistência plena de resiliência e criatividade em uma mesma hierarquia sistêmica. Um ser humano pode, assim, ao mesmo tempo se adaptar e buscar o melhor lugar do seu meio, ou simultaneamente criar um ambiente e procurar o retorno máximo dele, mas nunca se enquadrar e inovar radicalmente (BATESON, 1972). Por que, então, reconhecidos os imensos benefícios da resiliência (RAMIRES, 2004), se engajar na criatividade? Acredita-se que a resposta sistêmica para essa questão esteja em uma perspectiva futura da unidade mais básica ou na compreensão mais ampla que essa mesma unidade tem das dimensões 
do seu ambiente. A Figura 10 mostra que, por mais que um contexto imediato aparente estar em perfeita harmonia com a sua grandeza superior, sempre haverá uma estrutura ainda maior que possivelmente demandará transformações para evitar as extinções, sejam elas biológicas, psicológicas ou sociais.

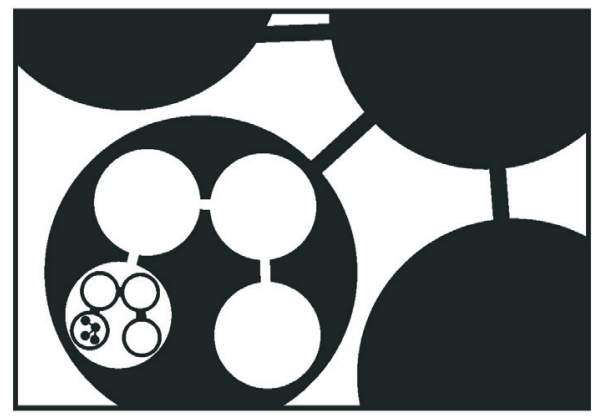

Figura 10: Hierarquia Sistêmica de Quarto Nível [Fonte: Autor]

Destarte, a criatividade de um sistema-indivíduo em sua família, por exemplo, é nada mais que a condição sine qua non da resiliência do seu respectivo sistema-família, pois, o que provoca a reorganização e, por conseguinte, a adaptação de uma coletividade a um novo contexto, é justamente o empreendedorismo individual. Tal perspectiva é coerente com o discurso de Walsh (2002), no qual a resiliência familiar, então, é o fortalecimento das capacidades de lidar com as crises ou adversidades que ameaçam o grupo como um todo, por meio da flexibilidade.

As transformações básicas de um sistema, logo, caracterizam-se pela irrefreável relação de homeostase entre uma parte e o todo, seja ela em níveis adjacentes, seja ela em dimensões bastante afastadas. Ao se estudar os seres humanos e suas configurações sociais, no entanto, é preciso, além de definir as ações de homeostase, se atentar igualmente para a força da vincularidade, dada a relevância dos vínculos nas coletividades. Passa-se, então, para a análise das transições familiares, instâncias da vida cotidiana em que não raro faz-se necessário equacionar até que ponto os ganhos em homeostase compensam as distorções entre os atratores.

\section{As TRANSFORMAÇÕES FAMILIARES}

Uma família, para começar, costuma ser entendida sob diversos pontos de vista: sua caracterização, sua função, sua posição histórica e, é claro, seu papel no ciclo vital. É certo, no entanto, que sob qualquer perspectiva adotada os arranjos familiares cumprem facilmente os prerrequisitos para serem considerados sistemas complexos. Seja um conjunto social que exerce marcada influência sobre a vida das pessoas (PRATTA; SANTOS, 2007), seja um grupo ativamente atuante nos acontecimentos sociais (DESSEN; BRAZ, 2000), as famílias são, simultaneamente, unidades e coletividades nas sem fim dinâmicas de desenvolvimento humano. 
Diferentemente dos modelos sistêmicos mais genéricos, porém, nas famílias, por se tratarem do primeiro círculo de socialização humana, a força da vincularidade é tão, ou mais, influente na atitude individual que a busca racional por homeostase. Não raro, nos assuntos familiares, ocorrem casos em que, por mais que qualquer perspectiva externa condene um determinado vínculo, as partes da situação insistem na preservação dos elos em crise (princípio da auto-organização adaptativa). Nisso, as pesquisas e as intervenções que visem a manutenção da saúde familiar dependem, fundamentalmente, não só da compreensão das trocas desse nicho com o meio social em que está inserido, mas também do entendimento das relações entre os seus membros (PRATTA; SANTOS, 2007).

Dá-se o nome de ciclo vital familiar à dilatação temporal dessas trocas e relações que conectam as distintas gerações de uma família e, ao mesmo tempo, evidenciam a trama de narrativas individuais dos membros que a compõem (CARTER; McGOLDRICK, 1995; CERVENY; BERTHOUD, 2002; MORÉ; QUEIROZ, 2007). O nascer, o crescer, o se reproduzir e o morrer das famílias, então, caracterizam-se como etapas ou fases nas quais as prioridades desses sistemas oscilam entre homeostase e vincularidade, sempre na tentativa de conciliar o equilíbrio coletivo com o crescimento pessoal. As quatro etapas a serem revisadas neste artigo são as mais comumente referidas na literatura, ditas, a fase de aquisição, a fase de adolescência, a fase de maturidade e a fase final da família.

A fase de aquisição engloba a escolha dos parceiros, a união efetiva da família por meios formais ou informais, a chegada dos filhos e a obtenção dos mais variados bens materiais (CERVENY; BERTHOUD, 2002; SANTOS; DIAS, 2008). Conforme exibe a Figura 11, o principal desafio das transições familiares presentes nessa etapa é a acomodação dos membros de uma mesma família em seu primeiro nicho e a diferenciação de cada indivíduo (CARTER; McGOLDRICK, 1995). Para Dessen e Braz (2000), uma das tarefas dos genitores nesse período é a busca pelo equilíbrio do sistema familiar, situação que exige, sobretudo, uma constante complementaridade dos seus papéis.

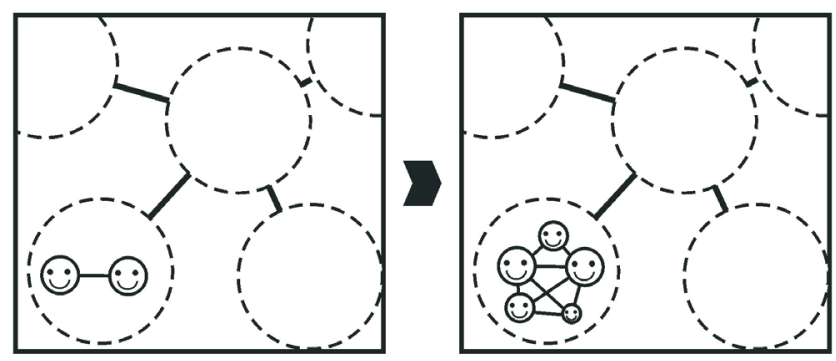

Figura 11: Família na Fase de Aquisição [Fonte: Autor]

Em seguida, atinge-se a fase da adolescência familiar, esta delimitada pelo crescimento dos filhos, os quais experimentam a vida em direção à idade adulta (CERVENY; BERTHOUD, 2002; SANTOS; DIAS, 2008). Neste estágio, as relações interfamiliares (intersistêmicas), até então dominadas exclusivamente pelos pais, chegam ao alcance dos filhos, os quais passam a questionar seus genitores 
dado o desenvolvimento de, relações mais sólidas com o mundo exterior, e da sua própria concepção de mundo e equilíbrio (Fig. 12). Os adultos têm um papel central neste processo, uma vez que oferecem a base inicial aos mais jovens, provendo-lhes a bagagem de regras e normas essenciais para o convívio social, assim como atuando como modelos introjetados cujas atitudes serão transmitidas às gerações que os sucedem, sem que haja a criação de barreiras definitivas entre uma família e outra (CARTER; McGOLDRICK, 1995; PRATTA; SANTOS, 2007).
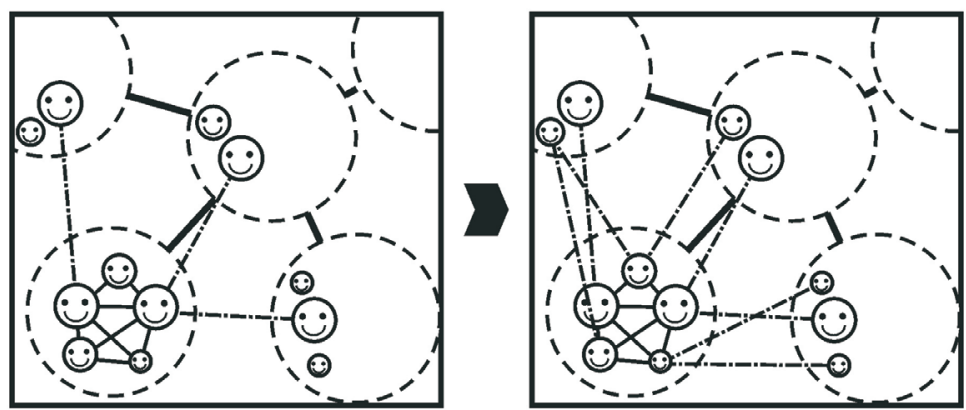

Figura 12: Família na Fase de Adolescência [Fonte: Autor]

A terceira etapa, por sua vez, consiste da fase da maturidade, essa composta de pais entre 50 e 60 anos e filhos já adultos, todos envoltos nos processos de saída de casa, de inclusão de uma terceira geração, de cuidado dos idosos e de anexo de parentes por afinidade (CERVENY; BERTHOUD, 2002; SANTOS; DIAS, 2008). Torna-se nítida a falta de divisórias entre os sistemas familiares, os quais, frequentemente, se sobrepõem, se dilatam, se constrangem, se confrontam e, até, se combinam (Fig. 13). A ocorrência das áreas de sombreamento, normativas ou não, marca os períodos de transição ecológica, nos quais as pessoas mudam a percepção que tem de si e dos outros em reação às alterações das suas posições ou dos seus papéis desempenhados no ambiente (MORÉ; QUEIROZ, 2007).
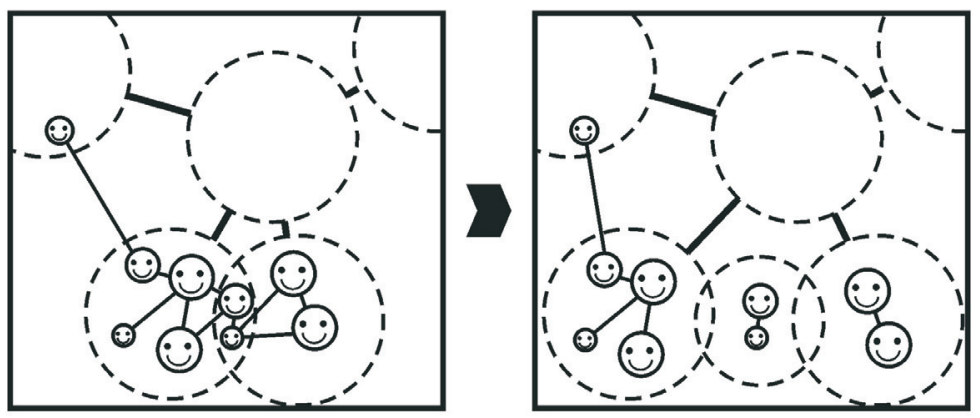

Figura 13: Família na Fase de Maturidade [Fonte: Autor]

Em remate, cita-se a fase final da família, a qual inclui eventos como o luto pela perda de amigos e parentes, a velhice, a viuvez, a aposentadoria, a perda de autonomia, a fragilidade física de alguns membros e a, em geral, dissolução do primeiro núcleo familiar (CERVENY; BERTHOUD, 2002; SANTOS; DIAS, 
2008). Esta etapa, mais que demarcar o fechamento do ciclo vital de um sistema, indica a sucessão dos vínculos interfamiliares, heranças sociais das gerações anteriores (Fig. 14). Para Santos e Dias (2008), dependendo do relacionamento estabelecido entre os membros de uma família, na sua última fase, o casal que volta a ficar sozinho pode enfrentar fenômenos como a "solidão compartilhada" e a "co-residência", ou acabar se tornando "pais estendidos".

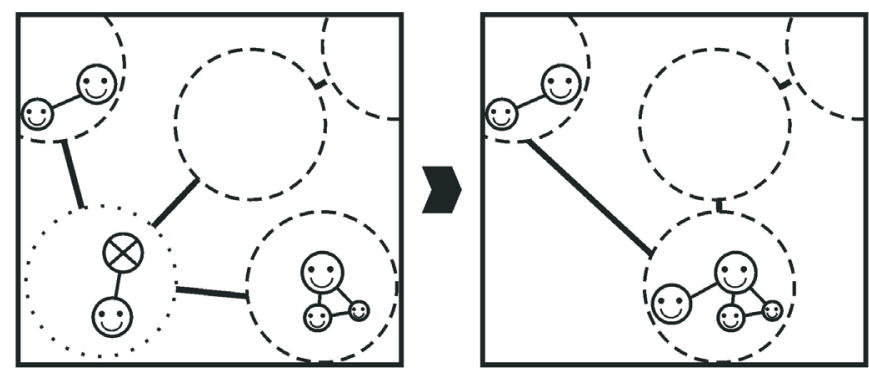

Figura 14: Família na Fase Final [Fonte: Autor]

Mais que representar patamares isolados de evolução, cada uma dessas etapas consiste de um frágil e momentâneo estado da entropia natural que circunda as famílias. Entre cada um desses pontos de referência encontram-se as transições familiares, movimentos de ida e de vinda que sinalizam os períodos críticos de desenvolvimento da individualidade pessoal e da "superpersonalidade" coletiva (KREPPNER, 2000). Sabendo, então, que a homogeneidade dos sistemas familiares, um dos mais importantes fatores de proteção (BRONFENBRENNER, 1970), não ocorrerá em um ambiente de estagnação, resta a compilação de diretrizes capazes de guiar a construção de um sistema harmônico em constante mutação.

Tais diretrizes, alicerçadas quase sempre no fortalecimento da resiliência familiar por meio da comunicação bem sucedida e da efetivação da criatividade individual, apontam atualmente para a habilidade de extrair significado das adversidades, para o compartilhamento de uma espiritualidade, para o aumento do número de vínculos, para a utilização de recursos sociais e financeiros e para o otimismo coletivo (CERVENY, 2004; WALSH, 2002). Como, todavia, cada transição familiar aumenta o risco de estressores verticais se somarem a estressores horizontais para criar um cenário de comunicação ausente ou contraditória (CARTER; McGOLDRICK, 1995), espera-se que a representação imagética dessas transformações sirva como uma ponte sólida para o diálogo efetivo, claro e consciente, objetivo final das mais diversas modalidades da terapia familiar (COSTA, 2010).

\section{CONSIDERAÇões FINAIS}

Através da ilustração dos atributos sistêmicos, este artigo buscou um meio capaz de sustentar paralelamente as mais diversas interpretações das transições familiares, movimentos das únicas redes sociais que certamente privilegiam a força da vincularidade em detrimento da homeostase. Independentemente da adoção dos referenciais de oito estágios (DUVALL, 1977), cinco estágios (SOLOMON, 1973), ou quatro estágios, como o utilizado neste artigo (CERVENY; 
BERTHOUD, 2002; MORÉ; QUEIROZ, 2007; SANTOS; DIAS, 2008), podese visualizar de maneira comum nas Figuras 11, 12, 13 e 14 os fenômenos mais marcantes, e portanto críticos, desses movimentos, que são a inclusão e a acomodação de novos membros, a perda do poder de exclusividade nas relações intersistêmicas, a sobreposição, o dilatamento, o constrangimento, a confrontação e a combinação de famílias inteiras, a sucessão hereditária dos vínculos e, acima de tudo, a coexistência de infinitas possibilidades de configurações familiares, todas delimitadas apenas por barreiras essencialmente efêmeras (eis o motivo dos sistemas familiares serem representados por linhas tracejadas, não cheias).

Sendo, então, cada vez mais evidente a ausência de um parâmetro único para a definição do contexto familiar (CARTER; McGOLDRICK, 1995), sugerese o deslocamento da perspectiva de funcionamento normal, que muitas vezes gera mais estereotipagens que vantagens, para a noção de funcionamento sistêmico pautado em relacionamentos harmônicos (WENDT; CREPALDI, 2008). Acredita-se que é possível um cenário de equilíbrio pleno entre unidade e coletividade, desde que haja interferências profissionais que valham-se simultaneamente de todos os princípios gerais dos conjuntos complexos. A configuração fractal da Figura 15, por exemplo, oferece a possibilidade ótima de auto-estabilidade adaptativa e auto-organização adaptativa, desde que o lugar ocupado por cada indivíduo, em comum acordo, seja temporário, já que as necessidades de cada um, impreterivelmente, serão alteradas com o dilatar do tempo.

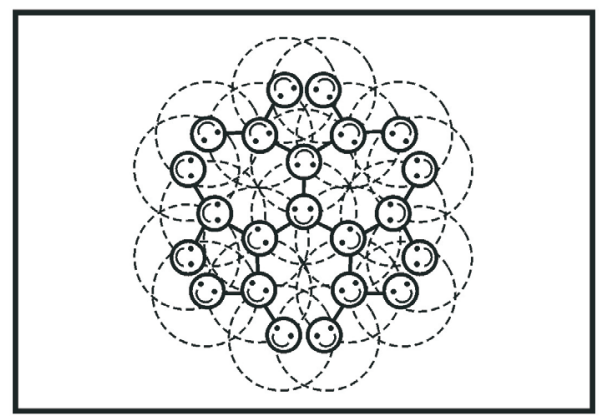

Figura 15: Sistema Harmônico [Fonte: Autor]

Nisso, para mudar o atual cenário de pura sorte e atingir um ambiente voltado, pelo menos, para a sorte por persistência ou para a sorte por preparo nas configurações familiares, sugere-se pesquisas que englobem ao menos três elementos do sistema familiar de cada vez (pessoa + pessoa + ambiente). Tais estudos podem se voltar para as influências genéticas de uma família, as suas práticas educativas, os hábitos de cuidado, as relações intergrupais com outras famílias, com a escola ou com o trabalho, as redes sociais de apoio familiar ou qualquer outro tema que acrescente ou explique os vínculos ou os "nós" desse sistema. Espera-se que este artigo contribua como uma ferramenta didática adequada ao nascimento de uma nova leitura das transições familiares. Do contrário, assim 
como sugere Bronfenbrenner (1979), as famílias continuarão enfrentando as suas crises da melhor maneira que elas podem e as políticas públicas continuarão tentando mudar somente as famílias e não as suas circunstâncias.

\section{REFERÊNCIAS}

BATESON, G. Steps to an ecology of mind: collected essays in anthropology, psychiatry, evolution, and epistemology. São Francisco: Chandler, 1972.

BATESON, G. Mente e natureza: A unidade necessária. São Paulo: Francisco Alves, 1979.

BOGACZ, R. Optimal decision-making theories: linking neurobiology with behavior. Trends in Cognitive Sciences, Cambridge, v. 11, n. 3, p. 118-125, mar. 2006.

BRENDTRO, L.; LONGHURST, J. The resilient brain. Reclaiming Children and Younth, Madison, v. 14, n. 1, p. 52-60, Spring. 2005.

BRONFENBRENNER, U. On the making of new men: some extrapolations from research. Canad. J. Behav. Sci., Ottawa, v. 1, n. 1, p. 4-24, jan./mar. 1969.

BRONFENBRENNER, U. Reaction to social pressure from adults versus peers among soviet day school and boarding school pupils in the perspective of an american sample. Journal of Personality and Social Psychology, Washington, v. 15, n. 3, p. 179-189, aug. 1970.

BRONFENBRENNER, U. Toward an experimental ecology of human development. American Psychologist, Washington, v. 32, n. 7, p. 513-531, jul. 1977.

BRONFENBRENNER, U. Contexts of child rearing: problems and prospects. American Psychologist, Washington, v. 34, n. 10, p. 844-850, oct. 1979.

BRONFENBRENNER, U. Ecology of the family as a context for human development: research perspectives. Developmental Psychology, Washington, v. 22, n. 6, p. 723-742, nov./dec. 1986.

BRONFENBRENNER, U.; CECI, S. Nature-nurture reconceptualized in developmental perspective: a bioecological model. Psychological Review, Washington, v. 101, n. 4, p. 568-586, out./dez. 1994.

CALAIS, S. et al. Stress entre calouros e veteranos de jornalismo. Estudos de Psicologia, Campinas, v. 24, n. 1, p. 69-77, jan./mar. 2007. 
CARTER, B.; McGOLDRICK, M. As mudanças no ciclo de vida familiar: uma estrutura para a terapia familiar. Porto Alegre: Artmed, 1995.

CERVENY, C. Família e: comunicação, divórcio, mudança, resiliência, deficiência, lei, bioética, doença, religião e drogadição. São Paulo: Casa do Psicólogo, 2004.

CERVENY, C.; BERTHOUD, C. Visitando a família ao longo do ciclo vital. São Paulo: Casa do Psicólogo, 2002.

COSTA, L. A perspectiva sistêmica para a clínica da família. Psicologia: Teoria e Pesquisa, Brasília, v. 26, n. especial, p. 95-104, 2010.

COX, M.; PALEY, B. Families as systems. Annu. Rev. Psychol., Palo Alto, v. 48, n. 1, p. 243-267, feb. 1997.

CRUZ, R. Saúde, trabalho e psicopatologias. In: AUED, B. Traços do trabalho coletivo. São Paulo: Casa do Psicólogo, 2005. p. 201-236.

DESSEN, M.; BRAZ, M. Rede social de apoio durante transições familiares decorrentes do nascimento de filhos. Psicologia: Teoria e Pesquisa, Brasília, v. 16, n. 3, p. 221-231, set./dez. 2000.

DUVALL, E. Marriage and family development. Filadélfia: Lippincott, 1977.

HAYES, J. Cognitive processes in creativity. In: GLOVER, J.; RONNING, R.; REYNOLDS, C. Handbook of creativity: Perspectives on individual differences. New York: Plenum, 1989. p. 135-145.

JOHNSON, E. Ecological systems and complexity theory: toward an alternative model of accountability in education. Complicity, Columbia, v. 5, n. 1, p. 1-10, 2008 .

KREPPNER, K. The child and the family: interdependence in developmental pathways. Psicologia: Teoria e Pesquisa, Brasília, v. 16, n. 1, p. 11-22, jan./abr. 2000 .

KUNCEL, N.; HEZLETT, S.; ONES, D. Academic performance, career potencial, creativity, and job performance: can one construct predict them all? Journal of Personality and Social Psychology, Washington, v. 86, n. 1, p. 148-161, jan./jun. 2004.

MASSIRONI, M. Ver pelo desenho: aspectos técnicos, cognitivos e comunicativos. Lisboa: 70, 1982. 
MORÉ, C.; QUEIROZ, A. Migração, movimento e transformação: irrupção do novo nas relações familiares. In: CERVENY, C. Familia em movimento. São Paulo: Casa do Psicólogo, 2007. p. 54-68.

OLIVEIRA, D. et al. Impacto das configurações familiares no desenvolvimento de crianças e adolescentes: uma revisão da produção científica. Interação em Psicologia, Curitiba, v. 12, n. 1, p. 87-98, jan./jun. 2008.

PRATTA, E.; SANTOS, M. Família e adolescência: a influência do contexto familiar no desenvolvimento psicológico de seus membros. Psicologia em Estudo, Maringá, v. 12, n. 2, p. 247-256, maio/ago. 2007.

RAMIRES, V. As transições familiares: a perspectiva de crianças e préadolescentes. Psicologia em Estudo, Maringá, v. 9, n. 2, p. 183-193, maio/ago. 2004.

SANTOS, I.; DIAS, C. Homem idoso: vivência de papéis desempenhados ao longo do ciclo vital da família. Aletheia, Canoas, v. 27, n. 1, p. 98-110, jan.jun. 2008 .

SOLOMON, M. A developmental conceptual premise for family therapy. Family Process, Malden, v.12, n. 2, p. 179-188, apr./jun. 1973.

STERNBERG, R. A propulsion model of types of creative contributions. Review of General Psychology, Washington, v. 3, n. 2, p. 83-100, jul,/sep. 1999.

VASCONCELlOS, M. Pensamento sistêmico: o novo paradigm da ciência. Campinas: Papirus, 2002.

VON BERTALANFFY, L. The theory of open systems in physics and biology. Science, New York, v. 111, n. 2872, p. 23-29, jan. 1950a.

VON BERTALANFFY, L. An outline of general system theory. British Journal of Philosophy, Oxford, v. 1, p. 139-164, 1950b.

VON BERTALANFFY, L. Teoria Geral dos Sistemas. 3. ed. Tradução de Francisco Guimarães. Petrópolis: Vozes, 1977.

WALSH, F. A family resilience framework: innovative practice applications. Family Relations, Hoboken, v. 51, n. 2, p. 130-138, apr./jun. 2002.

WATZLAWICK, P.; WEAKLAND, J.; FISCH, R. Mudança: princípios de formação e resolução de problemas. São Paulo: Cultrix, 1977. 
WENDT, N.; CREPALDI, M. A utilização do genograma como instrumento de coleta de dados na pesquisa qualitativa. Psicologia: Reflexão e Crítica, Porto Alegre, v. 21, n. 2, p. 302-310, maio/ago. 2008.

Recebido em: 21 de julho de 2010 Aceito em: 01 de fevereiro de 2012 